\title{
Phthalate Toxicity
}

\section{Arjun Suresh" and Tanu Jindal}

\author{
Amity Institute of Environmental Toxicology and Safety Management \\ Amity University, Noida, India \\ Corresponding Author: Arjun Suresh
}

Email: asuresh@amity.edu

\begin{abstract}
Phthalates are esters of Pthalic acid, compounds mainly used as plasticisers. Phthalates are widely used chemicals which are of significant research interest as their exposure causes various consequences for human health. There are several categories of phthalates extensively used in many commercial productions with diverse uses, physicochemical properties and toxicological effects. This chapter discusses the toxicity of Phthalates and its potential risks to human health.
\end{abstract}

Keywords: Phthalate; toxicity; DEHP; health

\subsection{Introduction}

Some commonly used phthalates are DEHP used as sealants, solvent fragrance, detergents, pharmaceuticals, cosmetics, paints and Butyl Benzyl Phthalate (BBzP) used as adhesives in vinyl materials (K. M. Rodgers, 2014). The widespread use of phthalates leads to its distribution in general environment as well as in raw food materials, contamination can also occur during processing of food. Larger volume of phthalates are used in edible products (above 40\%) in order to get high plasticizing effect. Some toxicologically relevant phthalates in food industry are DEHP, BBP, DnBP, DiBP etc. Another source of phthalates is paper and cardboard materials generated from recycled fibre (O. Kappenstein, 2012). The major cause of exposure of phthalates in human occurs through inhalation and ingestion, DEHP is the major phthalate that is present in hygienic materials such as shampoo, conditioners etc. Phthalates are cancerous for animals and can lead to fatal death and particularly reproductive toxicity in animals ( G. Latini, 2005). In this chapter an effort has been made to analyse the phthalates toxicity in various sources. 


\subsection{Toxicity of Phthalates}

In recent decades, belief over the adverse impacts of phthalates on human beings has been taken into consideration by the researchers despite the fact phthalate toxicity is already acknowledged since 1950s. Studies performed on animals have revealed the fundamental side effects including reproductive system toxicity. The physical and chemical properties of phthalates differ with the molecular structure which may comprise of a vapour phase with a low vapour pressure. Phthalates are typically fat soluble, which affect their leaching and segmentation. The exposure of phthalate in human can also arise as a result of materials encompassing phthalates across one product to other as can happen with food packaging material or intra cutaneous fluids, or through surrounding environment. Phthalate assimilation can occur through food comprising pharmaceuticals and other nutritional supplement (Ted Schettler, 2005). DEHP is one of the most common plasticizers used to make plastic flexible. DEHP having chemical formula of $\mathrm{C}_{24} \mathrm{H}_{38} \mathrm{O}_{4}$ and molecular weight equal to $390.56 \mathrm{gmol}^{-1}$ consists of a pair of eight carbon esters linked to a benzene carboxylic acid ring.

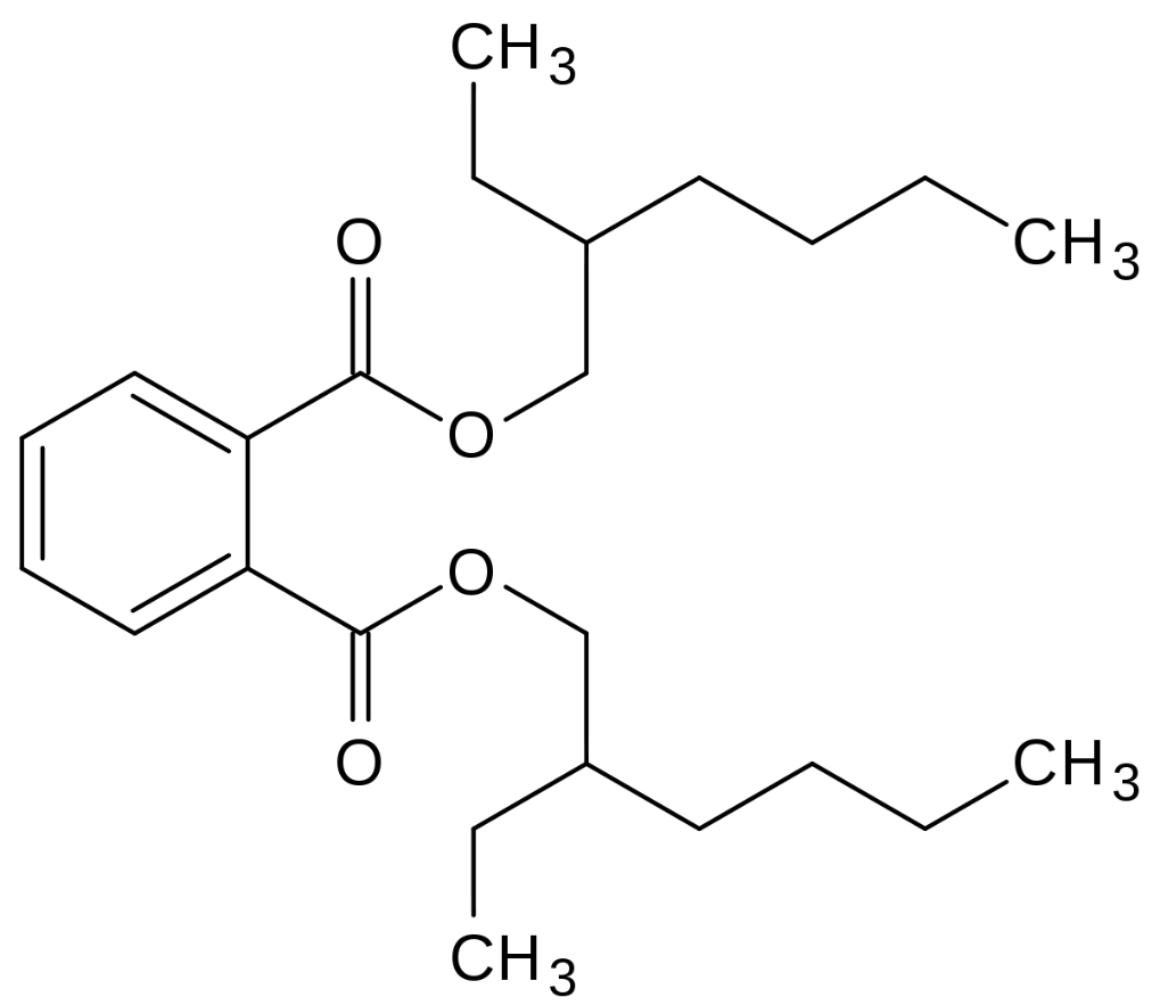

Figure 1.1: Structure of DEHP. 


\subsubsection{Reproductive and Developmental Toxicity of Phthalates}

Phthalates acquires endocrine-disrupting properties and their exposure to high concentrations will lead to fatal death, cancer, deformations, liver and kidney damage and reproductive toxicity in animals. In human beings, major problem have been arisen related to detrimental effects. Consequent exposure to phthalates during their development, phthalates can be transferred from maternal blood to developing foetus and into infants through breast milk and these exposures may impact the endocrine system which is critical for various biological functions involving reproductive functions. In addition phthalates were also found in breast milk, seminal fluid and placenta. Phthalates may also unfavourably affect other functions such as metabolic processes, thyroid signalling and immune system. (Jan L. Lyche et al, 2016)

\subsubsection{Phthalate Toxicity in Food}

Food is the major source of exposure of phthalates in humans, European Food Safety Authority (EFSA) through speculations of scientists on food preservatives, additives and materials has determined the tolerable daily doses (TDI) for some major phthalates and evaluated that exposure of phthalates in human through dietary products is within the estimated TDI set between 0.03 to $0.2 \mathrm{mg} / \mathrm{kg}$ of body weight. Generally phthalates used in food material such as tubes, conveyer belt and disposable material have been found as a major source of phthalate contamination. (European Food Safety Authority; 2005, Pasquale Ventrice, 2013)

\subsubsection{Phthalate Toxicity in Water}

The aquatic environment is a significant reservoir of phthalates receiving the waste water discharge, landfill leachate and rainfall. There has not been any estimation available regarding the presence of Phthalates at a national scale for recognizing their hazardous risk levels. In China the Environmental Quality Standards for Surface Water and Standards for Drinking Water Quality have regulated the limit values for phthalates (Xiaowie Lie, 2013).

Plastic bottles manufactured from Poly Vinyl Chloride (PVC) containing Phthalates used as plasticisers are used globally for packing drinking water; the usage of water bottles has been constantly rising worldwide over the recent few years (Imran Al-saleh, 2011). 


\subsubsection{Phthalate Toxicity in Cosmetics}

Phthalates are widely used in many applications such as skin care products (skin moisturizer, skin softeners), nail polish and sealants. There are number of phthalates reported to be found in cosmetics for example, DEHP, DEP(diethyl phthalate), DBP and DBB (dibutylbenzyl phthalate). Diethyl phthalate was noted to be present in 67 skin care products. 309 patents have been held including 120 nail polishes and enamels and 27 manicuring formations. These products may have adverse health impacts on human body through direct contact with skin, hair, nails and mucous membrane (Hyun Jung Koo, 2004).

\subsubsection{Phthalate Toxicity in Soil}

The main sources of phthalates in soil are waste water irrigation, pesticides, insecticides and other industrial productions. There are many pathways where phthalates are distributed in soil. The retention and transport of phthalates in soil is dependent upon the type of soil, anthropogenic actions and land usage whereas other weather factors (temperature, humidity) are also likely to affect the soil by the degradation and percolation of phthalates through soil profile. Phthalates contamination in soil also impact microbial population which is crucial for nutrient recycling, controlling pests and preservation of soil structure(Lizhi He, 2014).The lysimeter studies showed the presence of DEHP in both soil and leachate samples indicating that it could migrate to deeper soil layers causing groundwater contamination (Suresh, 2019).

\subsubsection{Phthalates Toxicity in Indoor Air and Dust}

People used to spend long time indoors and indoor source of contamination associated with constrained ventilation and slower contaminant degradation process leads to high pollutant levels. Polluted Indoor Air is found to be the most consequential environmental hazard to human health. Many endocrine-disrupting compounds (EDCs) such as plastics, detergents and other domestic products are reported as critically indoor contaminants (less studies has been done). Various researches have been done on many phthalates and are found to dominate indoor air. Diethyl phthalate (DEP) and di-n-butyl phthalate were reported at a high concentration in both air and dust. 
Table 1.1 Concentrations of phthalates in Environment and their toxic effects on human health.

\begin{tabular}{|c|c|c|c|c|c|}
\hline SN & Sources & $\begin{array}{c}\text { Phthalate } \\
\text { Compounds }\end{array}$ & $\begin{array}{c}\text { Observed } \\
\text { Concentration }\end{array}$ & Toxic Effects & References \\
\hline 1 & River Water & $\begin{array}{l}\text { DEP, DMP, BBP, } \\
\text { DEHP }\end{array}$ & $313-4640 \mathrm{ng} / \mathrm{l}$ & $\begin{array}{l}\text { Impacts aquatic } \\
\text { organisms (Increased } \\
\text { mortality, decreased } \\
\text { body weight and } \\
\text { distortion of sex ratio } \\
\text { in embryos) }\end{array}$ & $\begin{array}{l}\text { B R Ramaswamy et al, } \\
\text { (2014) }\end{array}$ \\
\hline 2 & Indoor Air & DEP, DBP, DEHP & Less than $10 \mathrm{ppb}$ & $\begin{array}{l}\text { Upper airway irritation } \\
\text { and Asthma }\end{array}$ & Karen Chou et al, (2006) \\
\hline 3 & Soil & $\begin{array}{l}\text { DMP, DEP, DnBP, } \\
\text { DnOP, DEHP and } \\
\text { BBP }\end{array}$ & $\begin{array}{l}0.032-6.29 \quad \mathrm{mg} \\
\mathrm{Kg}-1\end{array}$ & $\begin{array}{l}\text { Carcinogenic risk in } \\
\text { humans through } \\
\text { dietary pathways }\end{array}$ & L Niu et al, (2014) \\
\hline 4. & $\begin{array}{l}\text { Foodstuff } \\
\text { (Grain, bread } \\
\text { and cereal } \\
\text { products) }\end{array}$ & DEHP & $300 \mathrm{ug} / \mathrm{kg}$ & $\begin{array}{l}\text { Reproductive toxicity } \\
\text { in adults, insulin } \\
\text { resistance and type II } \\
\text { diabetes, obesity, } \\
\text { allergy, asthma, cancer }\end{array}$ & Serrano et al, (2014) \\
\hline 5. & $\begin{array}{l}\text { Personal care } \\
\text { products } \\
\text { (perfumes } \\
\text { shampoo, } \\
\text { skin } \\
\text { moisturizers) } \\
\text { Adhesives }\end{array}$ & $\begin{array}{l}\text { MMP,DEHP,DEP, } \\
\text { DBP,DBB }\end{array}$ & $4.6 \mathrm{ug} / \mathrm{l}$ & $\begin{array}{l}\text { Dermal toxicity, skin } \\
\text { inflammation, allergic } \\
\text { dermatitis }\end{array}$ & M. Mariama et al, (2016) \\
\hline
\end{tabular}




\subsection{Conclusion}

Presence of phthalates in the environment is hazardous for human health and ecosystem. Over the past decades, researches have indicated that phthalates can leach into the ecosystem from varying sources and affect human health and environment. Measures of phthalate toxicity vary widely according to phthalate type and its molecular structure. Leaching of Phthalate can lead to contamination of food, air, soil and water etc. which ultimately disturbs human health and environment. Various studies available on human health impact of phthalate are showing evidence of a wide range of adverse effects in the urinary tract, semen, pregnancy, reproductive tract, kidneys, lungs, foetus, and heart. Further studies have to be carried to understand the detailed pathway of Pthalate degradation to develop regulatory measures.

\subsection{References}

1. K. M. Rodgers and R. A.Rudel (2014), Toxicants in Food Packaging and Household Plastics,Molecular and Integrative Toxicology, DOI: 10.1007/978-1-4471-6500-22

2. O. Kappenstein et al (2012). A. Luch (ed.), Molecular, Clinical and Environmental Toxicology, DOI 10.1007/978-3-7643-8340-44

3. G. Latini (2005), Monitoring phthalate exposure in humans; Clinica Chimica Acta , doi:10.1016/j.ccen.2005.05.003

4. Pasquale Ventrice, (2013). Phthalates: European regulation, chemistry, pharmacokinetic and related toxicity; Environmental Toxicology and Pharmacology, 88-96

5. Ted Schettler. (2005), Human exposure to phthalates via consumer products ; Science and Environmental Health Network, doi:10.1111/j.1365-2605.2005.00567

6. Jan L. Lyche et al. (2016), Reproductive and Developmental Toxicity of Phthalates; Journal of Toxicology and Environmental Health, DOI: 10.1080/10937400903094091

7. Xiaowie Lie. (2013), Occurrence of phthalic acid esters in source waters: a nation widesurvey in China during the period of 2009-2012; Environmental Pollution, 184 262-270

8. Imran Al-saleh et al, ( 2011), Phthalates Residues in Plastic bottled water; The Journal of Toxicological Sciences, Vol. 36 No. 4 469-478 
9. Hyun Jung Koo, Byung Mu Lee.( 2004), Estimated Exposure to Phthalates in Cosmetics and Risk Assessment; Journal of Toxicology and Environmental Health, Part A, 67:1901-1914, DOI: $10.1080 / 15287390490513300$

10. Lizhi He \& Gerty Gielen \& Nanthi S. Bolan \& Xiaokai Zhang \& Hua Qin \& Huagang Huang \& Hailong Wang, (2014). Contamination and remediation of phthalic acid esters in agricultural soils in China: a review, DOI 10.1007/s13593-014-0270-1

11. Ruthan A. Rudel et al, (2003). Phthalates, Alkylphenols, Pesticides, Polybrominated Diphenyl Ethers,and Other Endocrine-Disrupting Compounds in Indoor Air and Dust; Environmental Science \& Technology, Vol 37, No. 20

12. Karen Chou, Robert O. Wright, (2006). Phthalates in food and medical devices; Journal of Medical Toxicology, Volume 2, Issue 3, pp 126-135

13. Lili Niu, Yang Xu, Chao Xu, Lingxiang Yun, Weiping Liu, (2014). Status of phthalate esters contamination in agricultural soils across China and associated health risks; Environmental Pollution 195 16-24

14. Krishna Kumar Selvaraj, Gomathy Sundaramoorthy ,Praveen Kumar Ravichandran, Girish Kumar Girijan, Srimurali Sampath ,Babu Rajendran Ramaswamy, (2014). Phthalate esters in water and sediments of the Kaveri River, India: environmental levels and ecotoxicological evaluations; Environ Geochem Health, doi:10.1007/s10653

15. Samantha S Serrano, Joseph Braun, Leonardo Trasande, Russell Dills, Sheela Sathyanarayana, (2014). Phthalates and diet: a review of the food monitoring and epidemiology data; Environmental health, doi: 10.1186/1476-069X-13-43)

16. Melissa Mariana, Joana Feiteiro, Ignacio Verde, Elisa Cairrao, (2016). The effects of phthalates in the cardiovascular and reproductive systems: A review; Environment International 94 758-776

17.Tai-Long Pan, Pei-Wen Wang, Ibrahim A. Aljuffali, Yi-Yun Hung, Chwan-Fwu Lin f,JiaYou Fang, (2014). Dermal toxicity elicited by phthalates: Evaluation of skin absorption, immune histology, and functional proteomics; Food and Chemical Toxicology 65 105-114

18. Suresh, A., Jindal, T., \& Khan, S. A. (2019). An integrated approach for risk assessment of groundwater contamination using lysimetric studies. Pollution Research, 38(2), 491-494. 
19. Suresh, A., \& Jindal, T. (2019). Lysimetric studies to estimate the solute and contaminant transport in hydrogeological profile. Ecology, Environment and Conservation, 25, S102-S105.

\section{$\underline{\text { Abbreviations }}$}

\begin{tabular}{|c|c|}
\hline Benzylbutyl phthalate & BzBP \\
\hline Dimethyl phthalate & DMP \\
\hline Di-n-butyl phthalate & DnBP \\
\hline Diethyl phthalate & DEP \\
\hline Di-2-ethylhexyl phthalate & DEHP \\
\hline Di-isononyl phthalate & DnOP \\
\hline Di-n-butyl phthalate & DnBP \\
\hline Benzyl butyl phthalate & BBP \\
\hline
\end{tabular}

